Technical Report

\title{
The impact responses and the finite element modeling of layered trapezoidal corrugated aluminum core and aluminum sheet interlayer sandwich structures
}

\author{
Cenk Kılıçaslan, Mustafa Güden*, İsmet Kutlay Odacı, Alper Taşdemirci \\ Dynamic Testing and Modeling Laboratory, Department of Mechanical Engineering, Izmir Institute of Technology, Gülbahçe Köyü, Urla, Izmir, Turkey
}

\section{A R T I C L E I N F O}

\section{Article history:}

Received 16 August 2012

Accepted 30 September 2012

Available online 23 October 2012

\begin{abstract}
A B S T R A C T
The impact responses of brazed and adhesively bonded layered 1050 H14 trapezoidal corrugated aluminum core and aluminum sheet interlayer sandwich panels with 3003 and $1050 \mathrm{H} 14$ aluminum alloy face sheets were investigated in a drop weight tower using spherical, flat and conical end striker tips. The full geometrical models of the tests were implemented using the LS-DYNA. The panels tested with spherical and flat striker tips were not penetrated and experienced slightly higher deformation forces and energy absorptions in $0^{\circ} / 90^{\circ}$ corrugated layer orientation than in $0^{\circ} / 0^{\circ}$ orientation. However, the panels impacted using a conical striker tip were penetrated/perforated and showed comparably smaller deformation forces and energy absorptions, especially in $0^{\circ} / 90^{\circ}$ layer orientation. The simulation and experimental force values were shown to reasonably agree with each other at the large extent of deformation and revealed the progressive fin folding of corrugated core layers and bending of interlayer sheets as the main deformation mechanisms. The experimentally and numerically determined impact velocity sensitivity of the tested panels was attributed to the micro inertial effects which increased the critical buckling loads of fin layers at increasingly high loading rates.
\end{abstract}

() 2012 Elsevier Ltd. All rights reserved.

\section{Introduction}

The corrugated structures are preferred in sandwich structures as the light-weight core materials. The corrugation leads to highly directional mechanical properties and provides high stiffness in certain applications [1]. The metallic corrugated core sandwich structures of light weight and relatively high crushing loads have the potentials to be used in the applications involving impact/blast load mitigation. There have been apparently numerous experimental and numerical investigations and reviews in the literature on the quasi-static/dynamic mechanical and impact/blast loading responses of the sandwich structures with periodic cellular metal cores, including honeycomb, corrugated and lattice truss topologies, for example see the review by Wadley in 2006 [2]. Liang et al. [1] investigated the optimum weight designs of metallic corrugated core structures in transverse and axial directions. The most effective parameters on the face sheet axial stress were shown to be corrugation length and face sheet thickness, while all geometrical parameters equally affected the core axial stress. Radford et al. [3] conducted projectile impact tests on triangular corrugated, pyramidal and bulk aluminum foam core sandwich plates. The corrugated and metal foam core sandwich plates exhibited the highest shock resistance among the tested palates. Lee et al. [4] investigated both experimentally and numerically the quasi-static and

\footnotetext{
* Corresponding author. Tel.: +90 232 7506001; fax: +90 2327506701 .

E-mail address: mustafaguden@iyte.edu.tr (M. Güden).
}

high strain rate (Hopkinson bar and gas gun tests) compression behavior of a unit stainless steel pyramidal truss core. The dynamic compression peak stresses of the Hopkinson bar tests were $60 \%$, and the peak stresses of the gas gun tests were 3-4 times higher than those of the quasi-static tests. The increased compressive stresses at increasingly high strain rates were attributed to the strain rate sensitive flow stress of stainless steel and inertial effects. The tested unit core exhibited a Type II structure, a classification made by Calladine and English [5] for the inertia sensitive structures. Rubino et al. [6,7] investigated the projectile impact response of clamped AISI 304 stainless steel Y-frame and corrugated core sandwich plates against aluminum foam projectiles. The plates experienced less deflection than beams and the ratio of permanent deflection of sandwich plates to monolithic plates increased with increasing incident impulse amplitude, while the face sheets of sandwich plates failed at relatively low impulse amplitudes as compared with monolithic plates. Tilbrook et al. [8] investigated the quasi-static and dynamic compression deformation behavior of AISI 304 stainless steel corrugated and Y-frame sandwich cores. The front and rear stresses of corrugated and Yframe cores were shown to be very similar and increased as the velocity increased. The corrugated structure was found to be more inertia sensitive than Y-frame core. Rubino et al. [9] investigated the quasi-static three-point bending and indentation behavior of simply supported and clamped AISI 304 stainless steel Y-frame and corrugated core sandwich beams. The initial peak strength of three-point loadings was found to be similar for both simply 


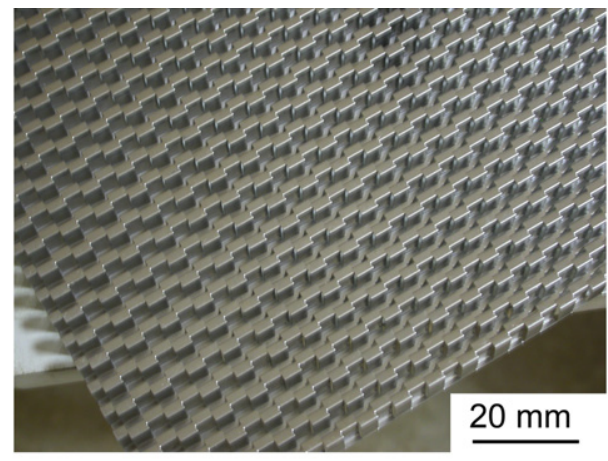

(a)

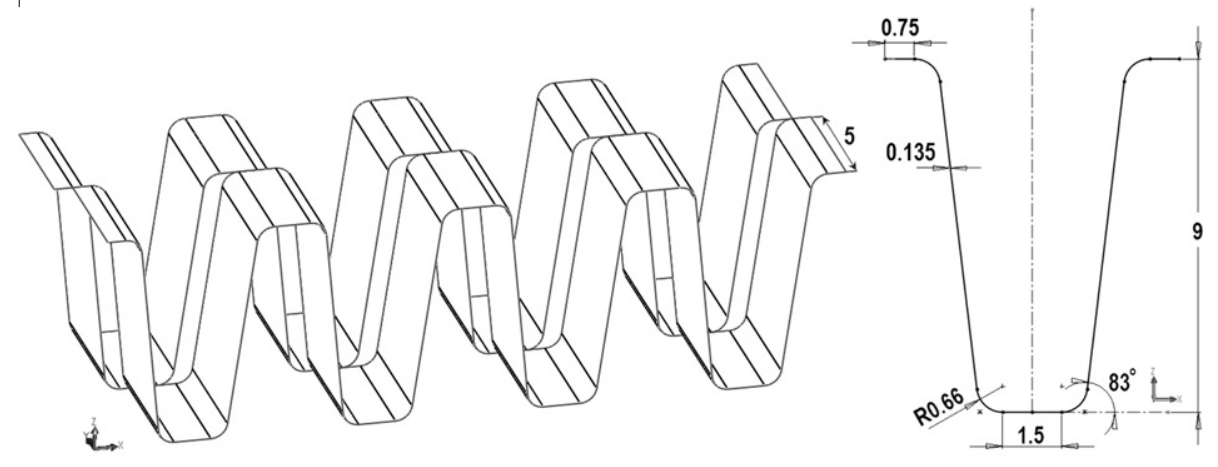

(b)

Fig. 1. (a) The picture of corrugated aluminum fin layer and (b) 3D model of the fins and unit fin geometrical parameters.

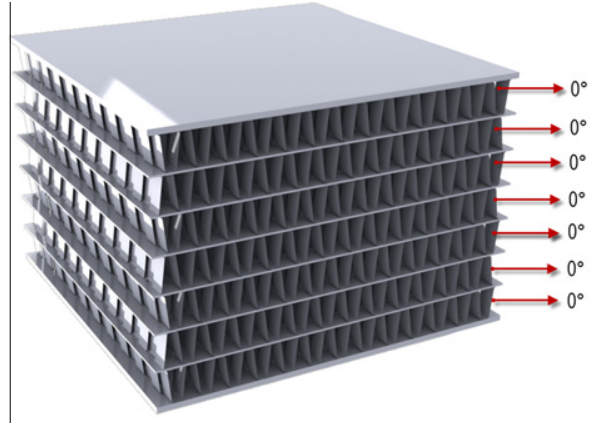

(a)

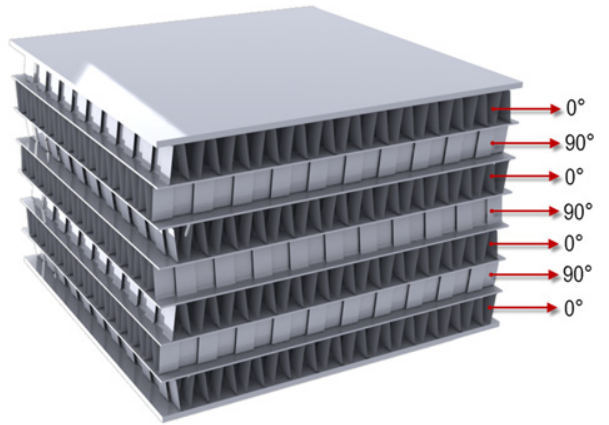

(b)

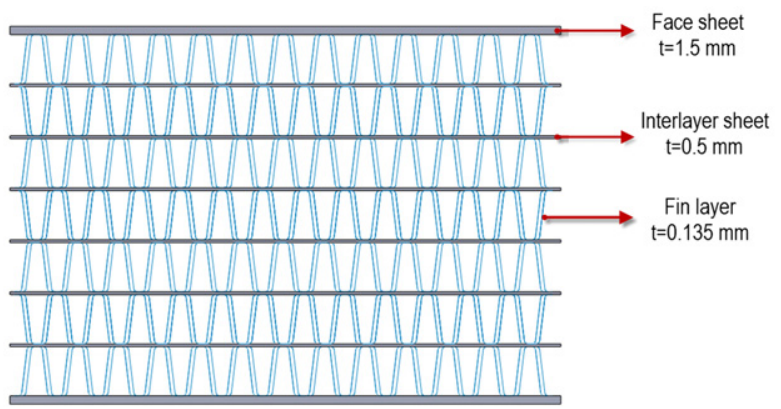

(c)

Fig. 2. 3D model of (a) $0^{\circ} / 0^{\circ}$ and (b) $0^{\circ} / 90^{\circ}$ fin layer oriented sandwich panels and (c) $2 \mathrm{D}$ model of $0^{\circ} / 0^{\circ}$ fin layer oriented sandwich panels.

supported and clamped beams, which was governed by core indentation. The simply supported beam exhibited a softening behavior following the initial peak strength, while the clamped beams showed a hardening response resulting from the longitudinal stretching of face sheets. Seong et al. [10] studied bending responses of mild steel sandwich panels with uni-directionally and 


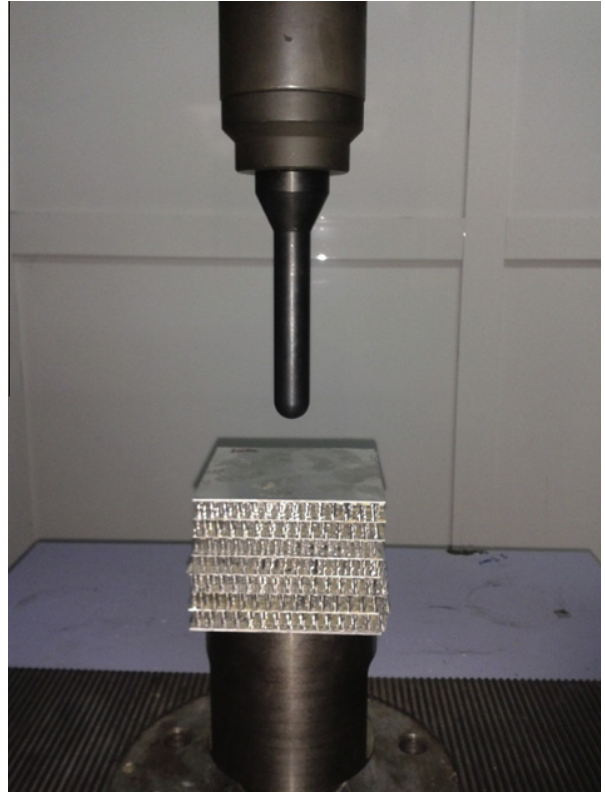

Fig. 3. Quasi-static indentation test set-up with spherical tip.

bi-directionally corrugated cores. Bi-directionally corrugated cores were found to increase the bending resistance of face sheets and reduce the anisotropic bending behavior of sandwich structures.

The aim of the present study was to investigate both experimentally and numerically the deformation and energy absorption capabilities of a layered aluminum corrugated sandwich panel used in conventional heat exchangers under low velocity impact. The investigated sandwich structure is different from the previously studied corrugated core sandwich plates in that it comprised aluminum sheet interlayers, which have the potent of distributing incoming impulse laterally to a larger deformation area. More, the corrugated core layer/fin was not straight but in zig-zag form to facilitate fluid flow and thermal conduction. The tests were performed at 3 and $6 \mathrm{~m} \mathrm{~s}^{-1}$ on the unclamped/simply supported sandwich panels (non-standard size) which were assembled through brazing and polyurethane adhesive bonding. The effects of striker tip type (spherical, conical and flat) and the corrugated layer orien- tations $\left(0^{\circ} / 0^{\circ}\right.$ and $\left.0^{\circ} / 90^{\circ}\right)$ on the deformation and energy absorption were determined. Lastly, a three-dimensional finite element model of the tested non-standard size specimens was developed using the LS-DYNA to validate the fidelity of the developed material and full geometrical test models for simulating the impact loading response of similar structures.

\section{Panel construction}

The sandwich structures were constructed by stacking the trapezoidal corrugated aluminum fin layers (Fig. 1a) and aluminum sheets in between the face sheets. The height, width and thickness of as-received fin layers are sequentially 9,5 and $0.135 \mathrm{~mm}$, depicted in Fig. 1b. The fin layers were commercially produced by a local factory in specified fin geometry. Three-dimensional models of $0^{\circ} / 0^{\circ}$ and $0^{\circ} / 90^{\circ}$ fin layer oriented sandwich panels are shown in Fig. 2a and b, respectively. The panels are comprised of three parts/components: (i) corrugated aluminum fin layers, (ii) aluminum sheet interlayers and (iii) aluminum face sheets. The fin and interlayer sheets are made of $1050 \mathrm{H} 14$ aluminum alloy and the face sheets are made of either 1050 H14 or 3003 aluminum alloy. The thicknesses of interlayer and face sheets are sequentially $0.5 \mathrm{~mm}$ and $1.5 \mathrm{~mm}$ as shown in Fig. 2c. Each panel is made of 7 -corrugated fin layers, 6 -interlayer sheets and 2 -face sheets. The panel components were brazed in a furnace at $600{ }^{\circ} \mathrm{C}$ for $10 \mathrm{~min}$ under atmospheric pressure using a 4343 aluminum filler sheet (6.6-8.2 wt\%), following the cleaning and flux slurry spraying of the surfaces. In another route, the fin layers and aluminum interlayer and face sheets were assembled using a polyurethane adhesive (Henkel Thomsit R710). The panels were kept under a weight of $10 \mathrm{~kg}$ for $2 \mathrm{~h}$ after applying a thin adhesive layer on the surfaces of the components. The densities of brazed and polyurethane bonded panels with 3003 and 1050 face sheets were similar: $\sim 370 \mathrm{~kg} \mathrm{~m}^{-3}$.The density of corrugated fin layer was $115 \mathrm{~kg} \mathrm{~m}^{-3}$, corresponding to a relative density of 0.042 .

\section{Quasi-static tension/indentation and low velocity impact tests}

The quasi-static tensile stress-strain curves of aluminum alloys were determined in a Shimadzu universal testing machine at the strain rate of $10^{-3} \mathrm{~s}^{-1}$. The tension test specimens were prepared

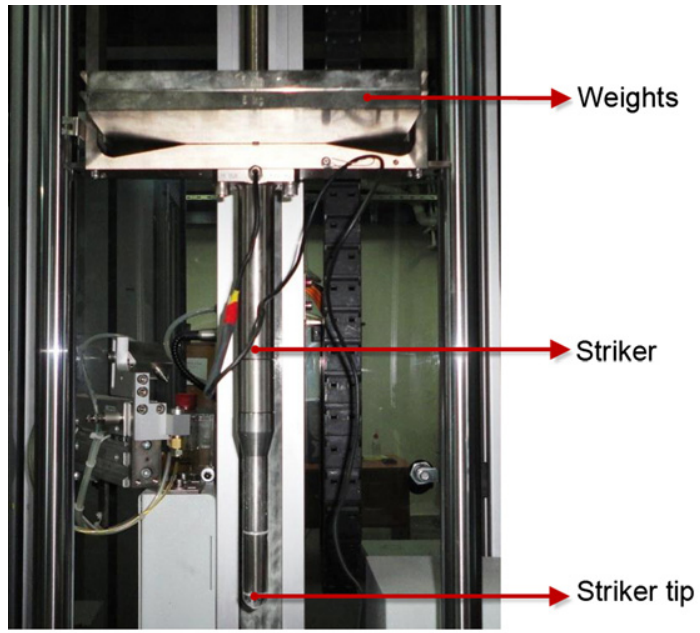

(a)
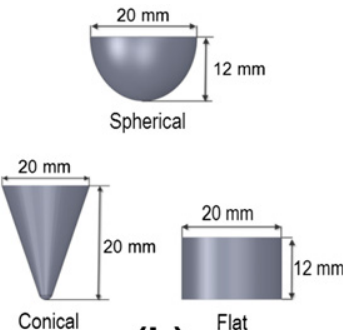

(b)

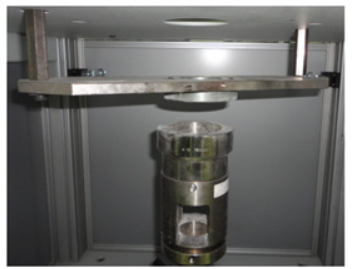

(c)

Fig. 4. Drop weight test system and parts: (a) impact set-up, (b) striker tips and (c) specimen holder rings. 
in accord with ASTM: E8/E8 M-11; the gage length: $60 \mathrm{~mm}$ and thickness: $1.5 \mathrm{~mm}$. The axial displacements of test specimens were recorded using a video extensometer. In order to determine the effect brazing on the stress-strain behavior, few specimens were passed through a heat treatment process, the same with the one applied in the brazing. These specimens were heated in a furnace from 200 to $600{ }^{\circ} \mathrm{C}$ in $13 \mathrm{~min}$, hold at $600^{\circ} \mathrm{C}$ for $2 \mathrm{~min}$; then, cooled to ambient temperature in air. Quasi-static indentation tests were performed on adhesively bonded $0^{\circ} / 0^{\circ}$ oriented corrugated sandwich panels (100 $\mathrm{mm}$ in length and width and $70 \mathrm{~mm}$ in height) using spherical indentation tip as shown in Fig. 3.

The impact test specimen sizes were the same with those of quasi-static indentation tests specimens, $100 \mathrm{~mm}$ in length and width and $70 \mathrm{~mm}$ in height. As-received brazed panels, $500 \times$ $500 \times 70 \mathrm{~mm}$ in size, were sliced into test specimen sizes using an electric discharge machine. Low velocity impact tests were per-

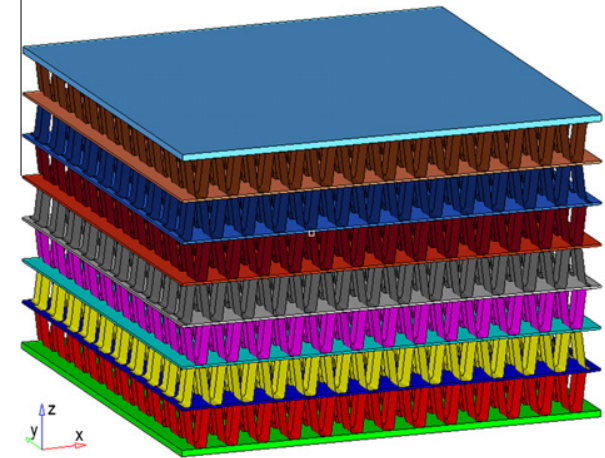

(a)

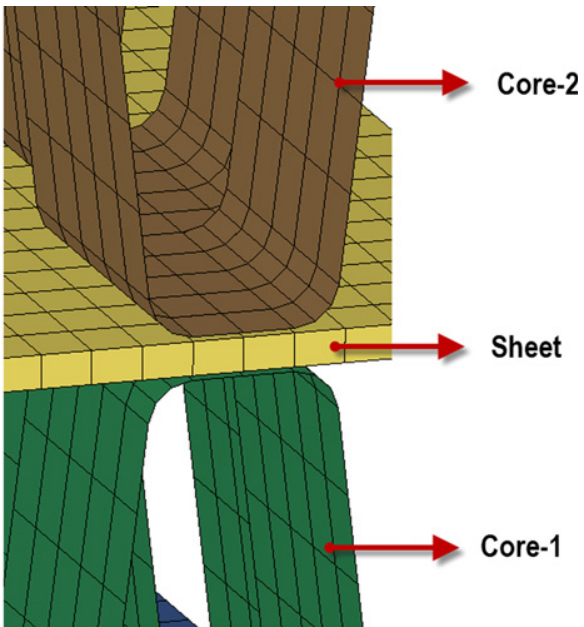

(b)

Fig. 5. (a) 3D FE model of corrugated sandwich panel and (b) contact area between fin layers and interlayer sheet.
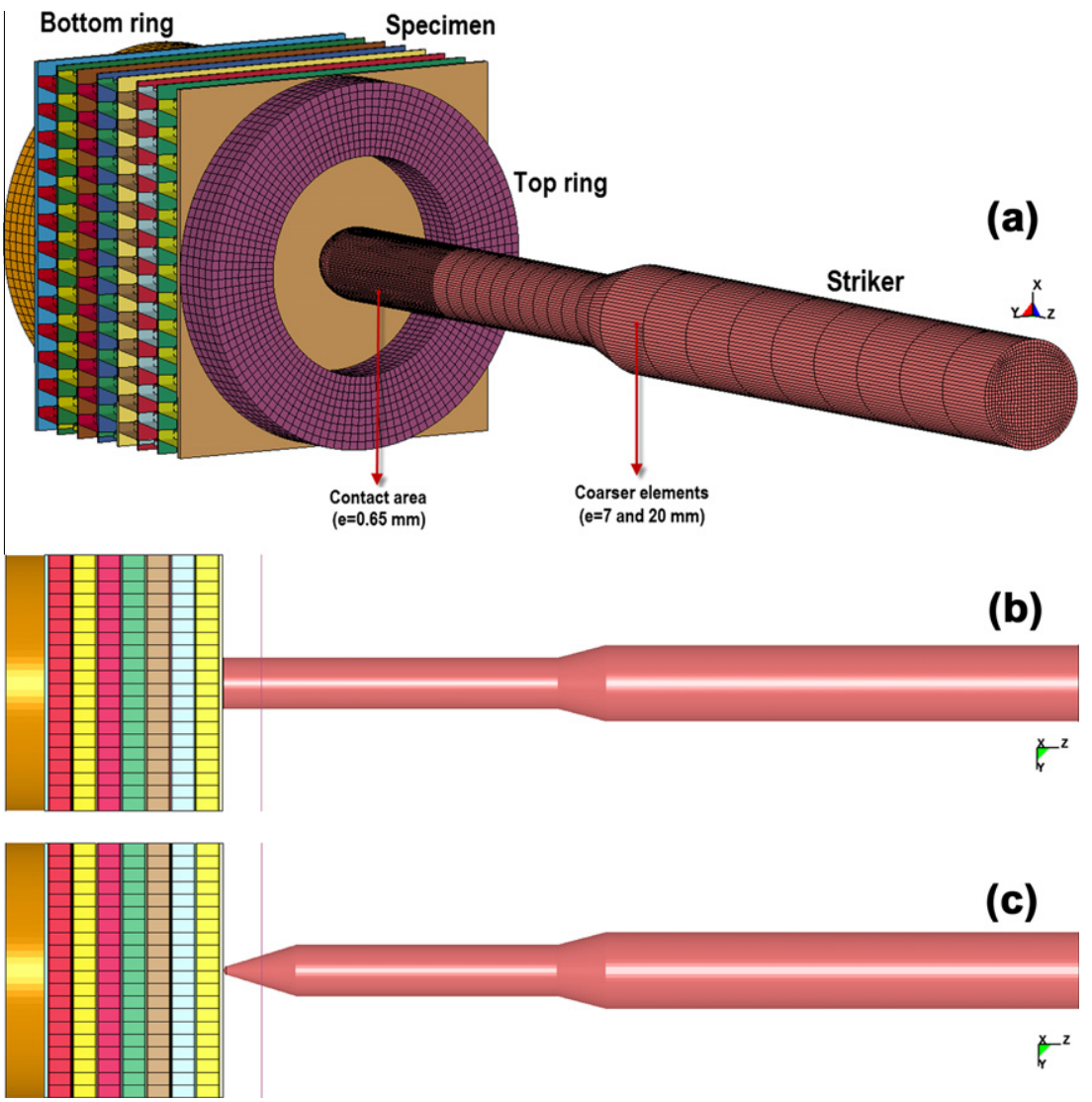

Fig. 6. FE model of drop weight test system with (a) spherical, (b) flat and (c) conical striker tip. 
formed in a FRACTOVIS drop weight tower. The main parts of the drop tower tester, striker holder, striker, weights, the striker tips and specimen holder rings, are shown in Fig. 4a-c. The striker was attached to a $90 \mathrm{kN}$ piezoelectric force transducer. The geometrical details and sizes of the used striker tips are shown in Fig. 4b. The striker velocity was measured by the photocells of drop weight tower. The energy absorption was calculated by integrating force-displacement curves. In a typical test, the specimen was inserted between the bottom and top rings (Fig. 4c); the bottom ring was clamped and the top ring exerted a clamping force to the specimen in order to prevent its motion. The clamping force should be as low as possible in order not to cause fin wall buckling. An applied clamping force of $20 \mathrm{~N}$ was determined to be causing no fin wall buckling and prevent the specimen motion. The total mass of the impact system was $15.778 \mathrm{~kg}$. The initial impact tests were performed at 3 and $6 \mathrm{~m} \mathrm{~s}^{-1}$ using spherical striker tip on brazed and adhesively bonded sandwich panels with 3003 aluminum face sheets. Later, the tests were conducted using flat and conical striker tips at $6 \mathrm{~m} \mathrm{~s}^{-1}$ on adhesively bonded sandwich panels with 1050 H14 aluminum face sheets.

\section{Numerical models}

The explicit full geometrical model of adhesively bonded $0^{\circ} / 0^{\circ}$ oriented corrugated sandwich panels with 1050 H14 aluminum face sheets is shown in Fig. 5a. The corrugated fin layers were meshed using quad Belytschko-Tsay shell elements with five integration points. This element formulation is capable of capturing deformation modes with a reasonable CPU calculation time $[11,12]$. As is seen in Fig. 5b, the finite element meshes of the interlayers and fin layers coincide with each other in order to satisfy tied contact definition, which eliminates arbitrary element size selection option. The face sheets and interlayer sheets were meshed using quad solid elements. The effect of mesh size on the numerical results was assessed by implementing (i) a fine mesh model, comprising 254800 shell and 243704 solid elements and (ii) a coarse mesh model, comprising 76440 shell and

Table 1

Material property of striker and rings used in the model.

\begin{tabular}{llll}
\hline Part & Density, & Elastic modulus, & Poisson's ratio, \\
& $\rho\left(\mathrm{kg} \mathrm{m}^{-3}\right)$ & $E(\mathrm{GPa})$ & 0 \\
\hline Striker & $9 \times 10^{4}$ & 210 & 0.3 \\
Rings & 7800 & 210 & 0.3 \\
\hline
\end{tabular}

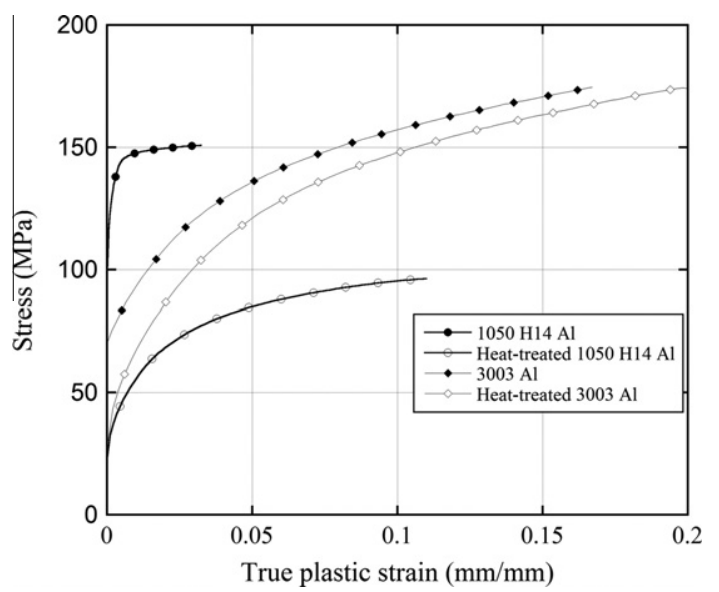

Fig. 7. True stress-true plastic strain curves of $1050 \mathrm{H} 14$ and 3003 aluminum alloys.
115064 solid elements. In order to capture the deformation realistically, a uniform element distribution was preferred in sheet meshing as suggested in Ref. [13].

The developed full numerical model of drop weight test system with spherical striker tip is shown in Fig. 6a. In the model, the striker and top and bottom rings were meshed using quad solid elements. The striker was modeled using three different mesh sizes

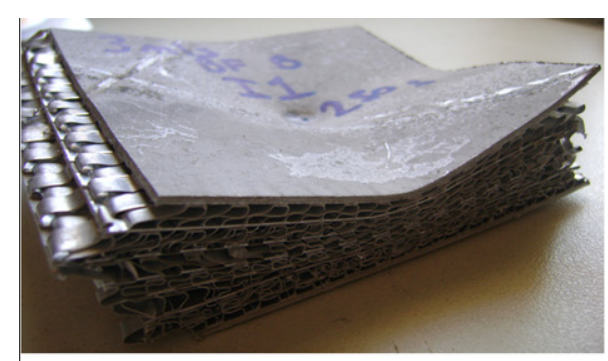

(a)

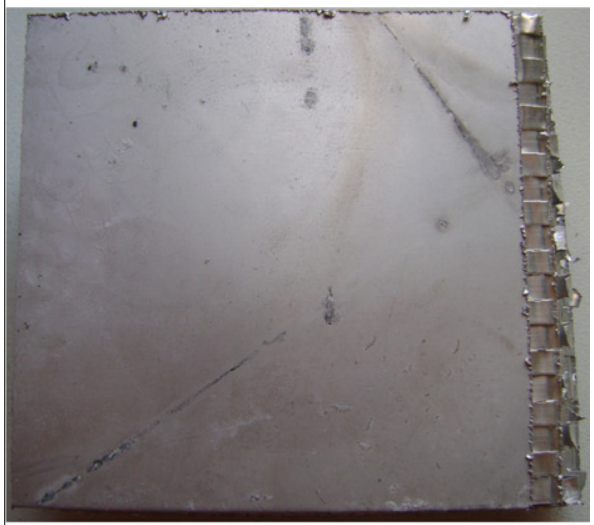

(b)

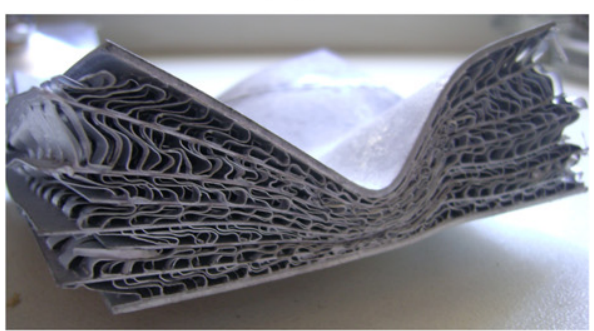

(c)

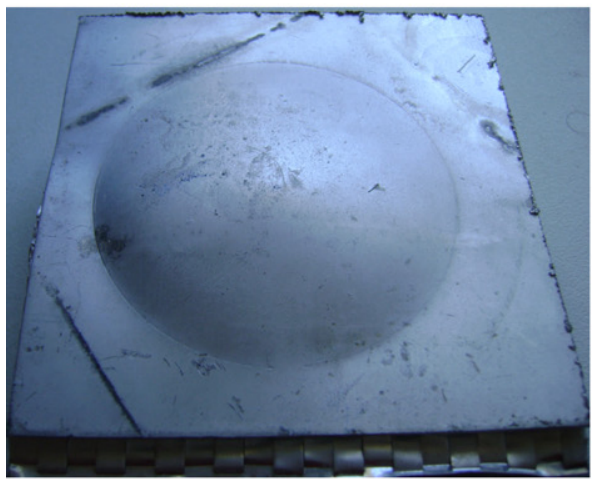

(d)

Fig. 8. (a) The isometric and (b) back face sheet pictures of brazed sandwich panels tested at $3 \mathrm{~m} \mathrm{~s}^{-1}$ and (c) the isometric and (d) back face sheet pictures of brazed sandwich panels tested at $6 \mathrm{~m} \mathrm{~s}^{-1}$. 
in order to reduce the element processing. The contact area was meshed using small elements $(0.65 \mathrm{~mm})$ and the length section using coarse elements ( 7 and $20 \mathrm{~mm}$ ), as seen in Fig. 6a. Total 74304, 5400 and 4200 solid elements were used to model striker and top and bottom rings, respectively. In the models with flat and conical striker tips, above-mentioned model parameters were kept the same and only the striker geometries were altered (Fig. 6b and $\mathrm{c}$ ).

MAT_SIMPLIFIED_JOHNSON_COOK material model, material type 98, was used to model $1050 \mathrm{H} 14$ aluminum alloy. Johnson and Cook (JC) flow stress model is given as [14]

$\sigma=\left[A+B \varepsilon^{n}\right]\left[1+\operatorname{cln}\left(\frac{\dot{\varepsilon}}{\dot{\varepsilon}_{0}}\right)\right]\left[1-\left(T^{*}\right)^{m}\right]$

where $\varepsilon, \dot{\varepsilon}$, and $\dot{\varepsilon}_{0}$ are, respectively, the effective plastic strain, strain rate, and reference strain rate; $A, B, n, c$, and $m$ are the model parameters. Material type 98 does not take into account temperature effect, the last bracket of Eq. (1). As aluminum alloys have no or negligible strain rate dependent flow stress; the second brackets of Eq. (1) is also omitted in the material model. The failure criterion was selected as the true plastic strain at failure. The striker and rings were modeled using MAT_RIGID material model, material type 20 . The density of the striker was proportionally increased to an impact mass of $15.775 \mathrm{~kg}$. The material model parameters of the striker and rings are further tabulated in Table 1 . The motion of the top and bottom rings in $\mathrm{x}, \mathrm{y}$ and $\mathrm{z}$-direction and the rotations in all directions were constrained, while the striker motion was only allowed in the z-direction. The clamp force was attained to the top ring by defining LOAD_SET_SEGMENT option in the LS-DYNA. The contacts were assumed to be perfectly bonded and a TIED_NODES_TO_SURFACE contact algorithm was attained between core, interlayer sheets and face sheets. ERODING_SINGLE_SURFACE contact definition was selected in order to take into account selfcontacting interfaces. ERODING_SURFACE_TO_SURFACE contact was defined between striker and sandwich panel. The contact between the rigid rings and sandwich panel was defined with AUTOMATIC_SURFACE_TO_SURFACE algorithm. The static and dynamic friction coefficients were set to 0.3 and 0.2 , respectively. CONTROL_SHELL card was also defined to include shell thickness in the contact algorithms. Since the total CPU time for the solution was determined to be relatively long (800 CPU hours), resulting from the element processing and intricate contact definitions, the mass scaling was applied by defining CONTROL_TIMESTEP card in the LS-DYNA.

\section{Results and discussion}

\subsection{Material properties}

The quasi-static true stress-true plastic strain curves of 1050 and 3003 aluminum alloys are shown in Fig. 7. The yield strengths of $1050 \mathrm{H} 14$ and 3003 alloys are determined to be $102 \mathrm{MPa}$ and $57 \mathrm{MPa}$, respectively. The yield strength of heat-treated 1050 and 3003 alloys are $24 \mathrm{MPa}$ and $28 \mathrm{MPa}$, respectively. The JC flow stress parameters of the studied $1050 \mathrm{H} 14$ alloy were determined by fitting the first bracket of Eq. (1) with the experimental true stresstrue plastic strain curves. The parameters are $A=102 \mathrm{MPa}$, $B=97.252 \mathrm{MPa}, n=0.18$ and $\varepsilon^{f}=0.62$.

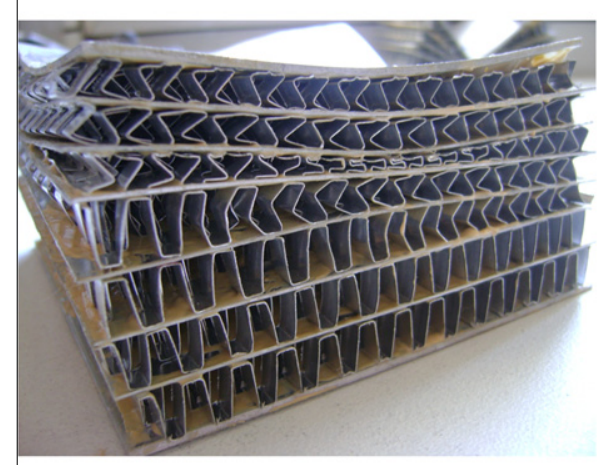

(a)

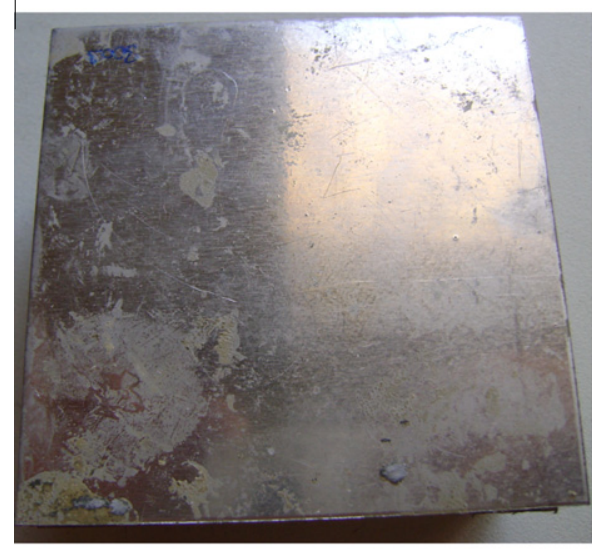

(b)

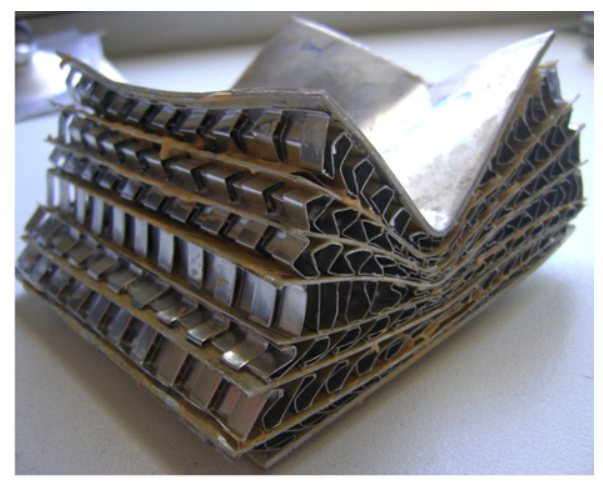

(c)

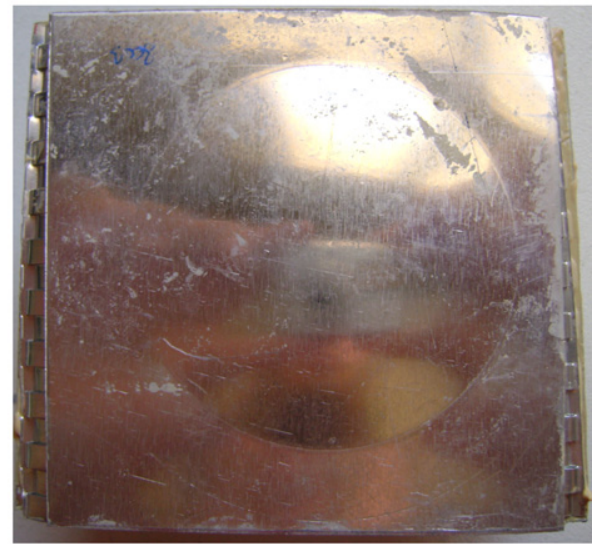

(d)

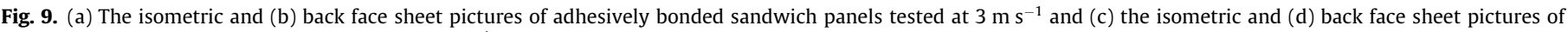
adhesively bonded sandwich panels tested at $6 \mathrm{~m} \mathrm{~s}^{-1}$. 


\subsection{Impact testing of brazed and adhesively bonded panels}

The isometric and back face pictures of brazed samples with 3003 alloy face sheets tested at 3 and $6 \mathrm{~m} \mathrm{~s}^{-1}$ using spherical striker tip are sequentially shown in Fig. 8a-d, respectively. The corrugated core and face sheets are seen to be excessively deformed: the fin layers are heavily crushed and the interlayer sheets are bent particularly at the striker impact zone. The main failure mechanism of the corrugated layer is the fin wall bending/folding as seen in Fig. 8a and c. It is also noted that a chequered surface is formed at the front face sheet due to localized plastic deformation. This effect is much more evident in the panels tested at $6 \mathrm{~m} \mathrm{~s}^{-1}$ (Fig. 8c). The back face deflections are 3 and $9 \mathrm{~mm}$ at 3 and $6 \mathrm{~m} \mathrm{~s}^{-1}$ impact velocities, respectively. The isometric and back face pictures of adhesively bonded panels with 3003 alloy face sheets tested at 3 and $6 \mathrm{~m} \mathrm{~s}^{-1}$ are sequentially shown in Fig. 9a-d, respectively. The progressive deformation of the panel tested at $3 \mathrm{~m} \mathrm{~s}^{-1}$ is seen in Fig. 9a; the first 4-5 fin layers are crushed via fin wall bending. The same deformation mechanism of fin wall bending is also observed in the panels tested at $6 \mathrm{~m} \mathrm{~s}^{-1}$ (Fig. 9c). No back face deflection is detected in the samples test at $3 \mathrm{~m} \mathrm{~s}^{-1}$ (Fig. 9b), while the back face deflection at $6 \mathrm{~m} \mathrm{~s}^{-1}$ is about $3 \mathrm{~mm}$ (Fig. 9d), which is less than that of brazed panels tested at the same impact velocity.

The force-displacement and energy-displacement curves of brazed and adhesively bonded panels tested at 3 and $6 \mathrm{~m} \mathrm{~s}^{-1}$ are

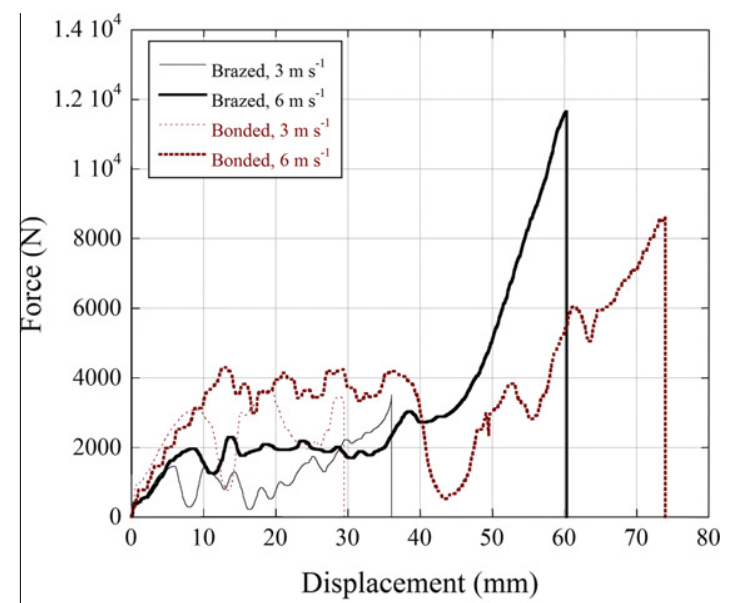

(a)

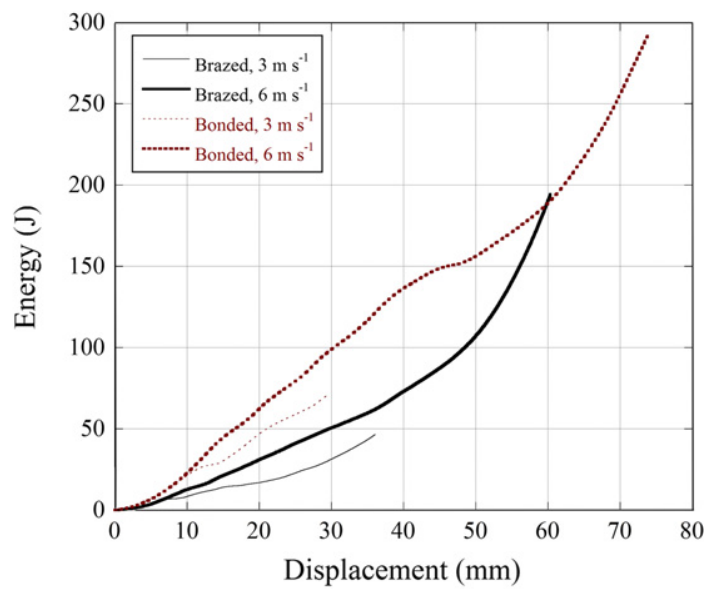

(b)

Fig. 10. (a) Force-displacement and (b) energy-displacement history of brazed and adhesively bonded panels tested at 3 and $6 \mathrm{~m} \mathrm{~s}^{-1}$. shown in Fig. 10a and b, respectively. Load instabilities are detected after the initial peak load in the plateau region (Fig. 10a). These post-buckling load fluctuations are due to the bending/buckling of the fin layers. Load instabilities were also detected in the corrugated and pyramidal cores under axial compressive loads [3,4,15-17]. Bonded panels exhibit about two times higher deformation forces than brazed panels at both impact velocities as depicted in Fig. 10a. The deformation of the corrugated layers in both panels is progressive fin wall buckling, starting from the impact zone. At large displacements, the deformation proceeds with the compression of folded layers and bent interlayer and face sheets altogether, leading to increased force values. This deformation type is analogous to the ductile metal foam deformation in the densification region $[18,19]$. The progressive core layer deformation was also reported in a multilayered pyramidal lattice structure with interlayer sheets under axial compressive loading [15]. The layer wise deformation continued until the layers were completely compacted. It is also seen that bonded panels absorb more energy than brazed panels (Fig. 10b). This is because of the lower flow stresses of aluminum alloys in the brazed sandwich panels. With the applied heat treatment, the flow stress of $1050 \mathrm{H} 14$ alloy is reduced from 150 to $68 \mathrm{MPa}$ at 0.2 strain (Fig. 7). The use of low strength core however comes with several advantages in the applications involving impact and blast loading. Low strength core in sandwich plates distributes the load more efficiently, reducing

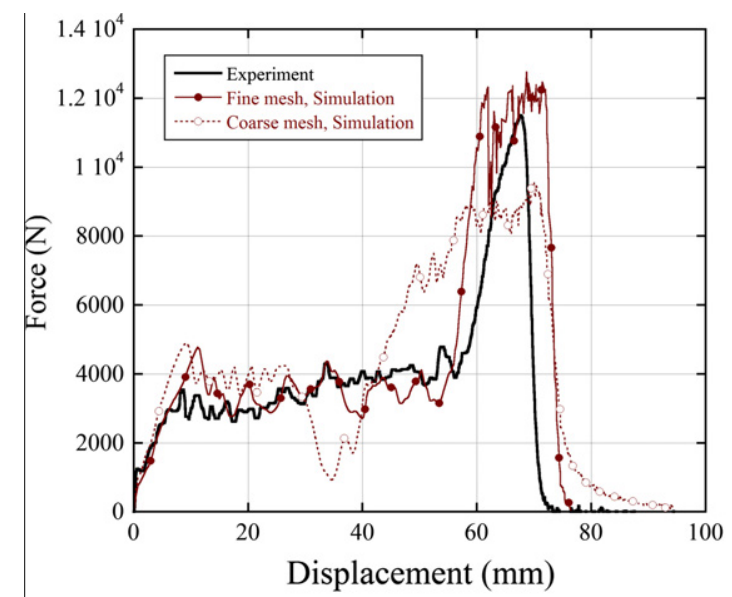

(a)

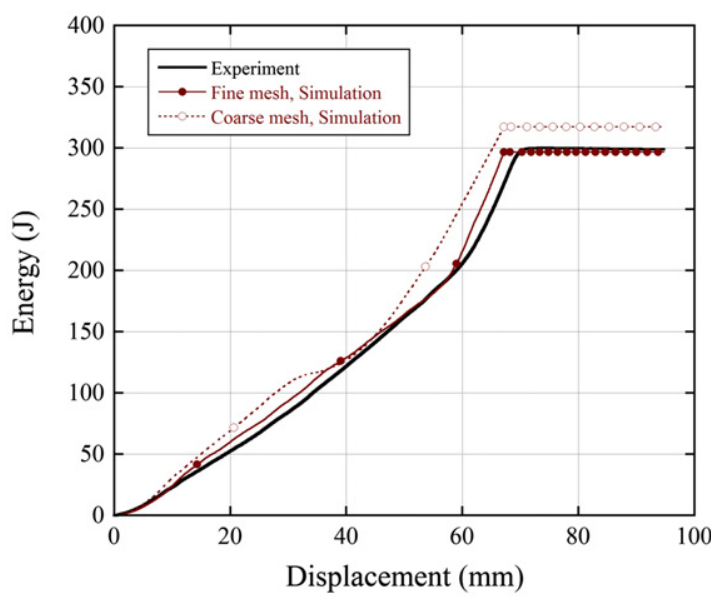

(b)

Fig. 11. Simulation and experimental (a) force-displacement and (b) energydisplacement curves of $0 \% 10^{\circ}$ adhesively bonded panels tested at $6 \mathrm{~m} \mathrm{~s}^{-1}$. 
the strain concentration near the point of the impact [9]. It also reduces the forces transmitted to back surface, providing more effective protections for the structures [20,21]. In accord with this, it is noted that low strength brazed panels (Fig. 8a and c) spread the deformation to a larger area compared to high strength bonded panels (Fig. 9a and c).

\subsection{Impact testing of adhesively bonded panels and numerical model}

Fig. 11a and b shows the experimental and numerical (fine and coarse mesh) force-displacement and energy-displacement curves of $0^{\circ} / 0^{\circ}$ fin layer orientated panels tested at $6 \mathrm{~m} \mathrm{~s}^{-1}$ using spherical striker tip. The experimental force and energy absorption values are well approximated using a fine mesh model than a coarse mesh model, because the coarse mesh model cannot capture the experimental force values above $30 \mathrm{~mm}$ displacements. The experimental back face deflection ( $3.2 \mathrm{~mm}$ ) is also well approximated using a fine mesh model $(3.5 \mathrm{~mm})$, while numerical model with coarse mesh gives a back face deflection of $2 \mathrm{~mm}$. Therefore, further simulation studies were continued using fine mesh model.

Typical experimental force-displacement curve of $0^{\circ} / 0^{\circ}$ and $0^{\circ} /$ $90^{\circ}$ and numerical force-displacement curve of $0^{\circ} / 0^{\circ}$ fin layer orientated panels tested at $6 \mathrm{~m} \mathrm{~s}^{-1}$ using spherical striker tip are shown in Fig. 12a. It is noted in the same figure that $0^{\circ} / 90^{\circ}$ fin layer orientated panel experiences higher loads than $0^{\circ} / 0^{\circ}$ fin layer orientated panel at the large extent of deformation. The numerical model load-displacement curve is noted well agree with the experimental curve in terms of crushing load values and force-displacement curve trends, showing the validity of used material models. The pictures of $0^{\circ} / 90^{\circ}$ and $0^{\circ} / 0^{\circ}$ fin layer orientated panels tested using spherical tip are sequentially shown in Fig. 12b and c. The final deformation shapes of the panels are very much similar in both orientations, but a higher lateral compression of the specimen is seen in $0^{\circ} / 90^{\circ}$ fin layer orientated panels. The striker tip excessively deforms the face sheets at the contact region without penetration into interior layers. The experimentally measured back face deflection of $0^{\circ} / 90^{\circ}$ fin layer oriented panel is $2 \mathrm{~mm}$, which less than that of $0^{\circ} / 0^{\circ}$ fin layer oriented panel $(3.2 \mathrm{~mm})$. The corresponding numerical model final deformed shape of $0^{\circ} / 0^{\circ}$ fin layer orientated panel is shown in Fig. 12d for comparison. The experimental and model final deformed final shapes of the panels are broadly similar. In the striker tip contact region, the ductile deformation and cracking of the face sheet are observed experimentally; however, the elements in the numerical model in the same region are deleted as the plastic strain criterion is reached; therefore, the layer under the face sheet is seen in numerical model in Fig. 12d. In accord with the experiments, the fin buckling/folding of the corrugated layers and bending of the face and interlayer sheets are the main deformation mechanisms for the numerically tested panels. The fin folding is also noted to be progressive: when the panel is initially loaded by the striker, the fins in the first layer start to buckle (Fig. 13a-c) and with the completion of the fin folding of

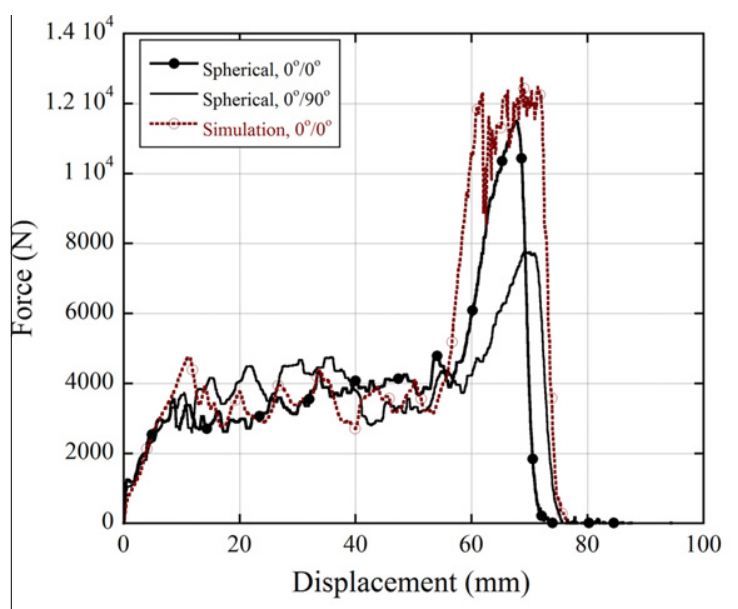

(a)

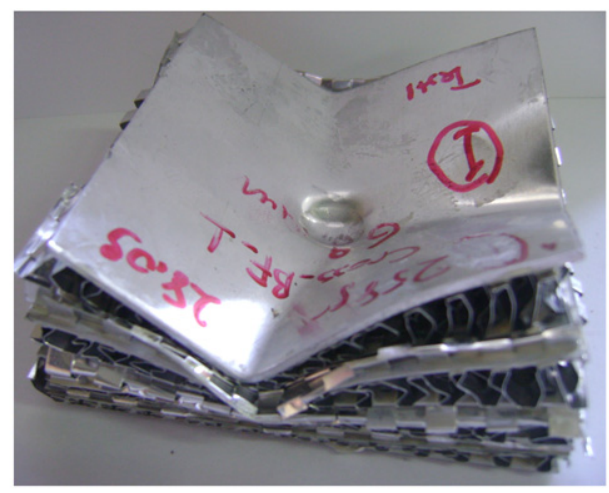

(b)

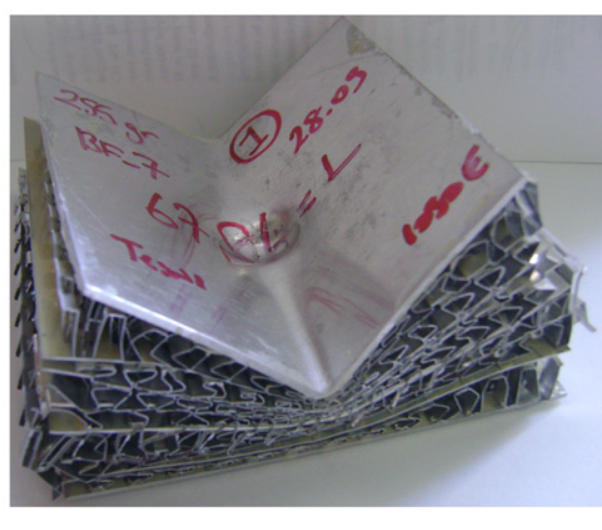

(c)

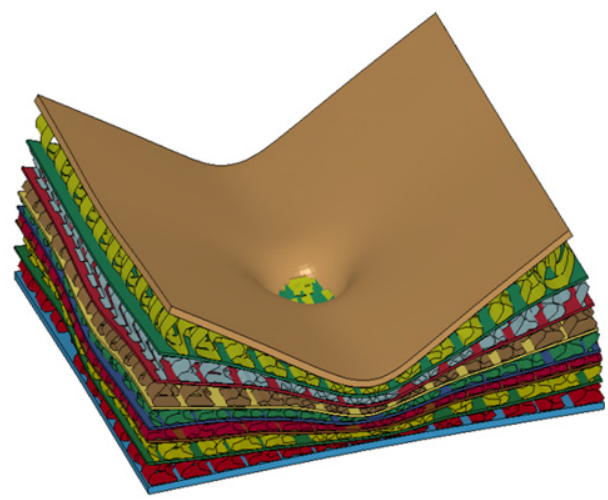

(d)

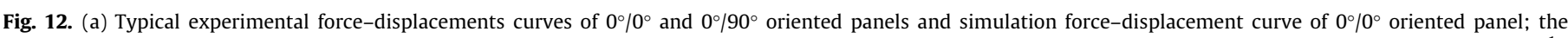

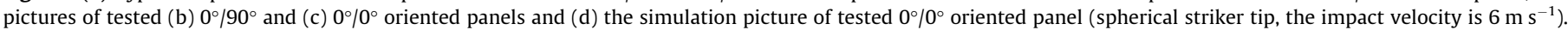




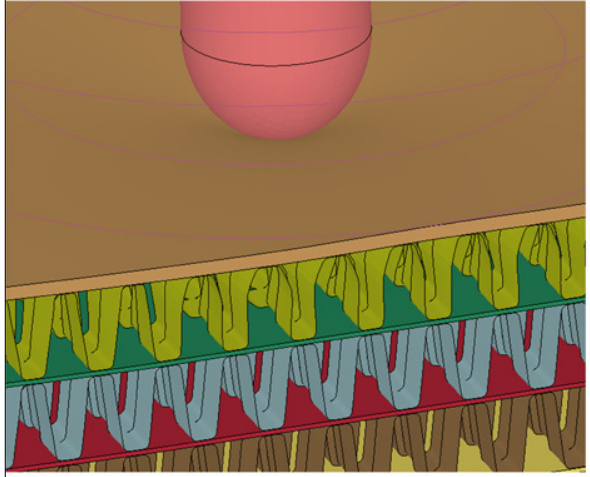

(a)

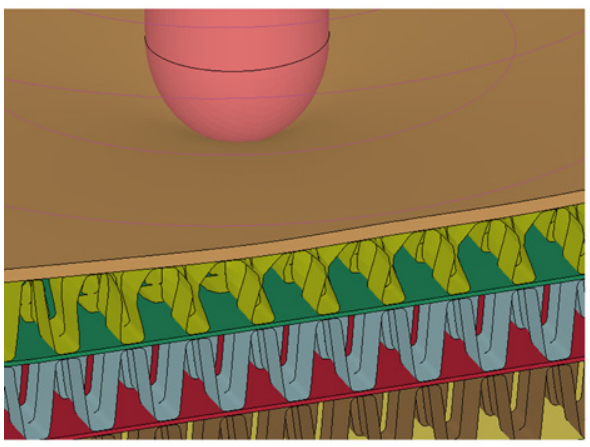

(b)

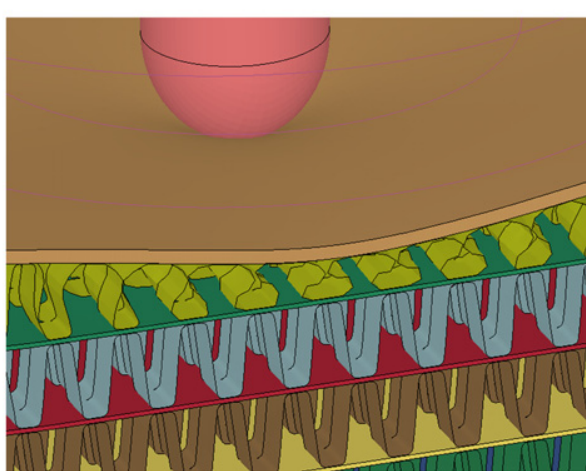

(c)

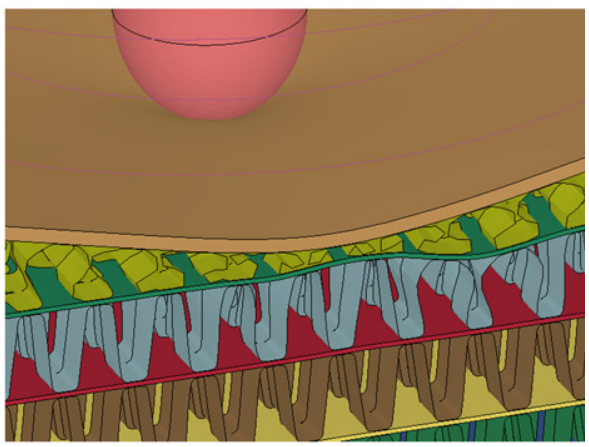

(d)

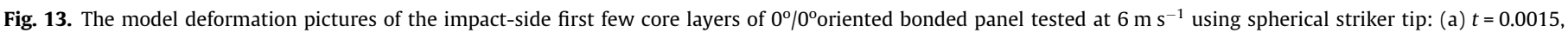
(b) $t=0.00174$, (c) $t=0.021$ and (d) $t=0.024 \mathrm{~s}$.

the first layer, the fins in the next layer start to buckle with the bending of the face sheet (Fig. 13d).

Typical experimental force-displacement curve of $0^{\circ} / 0^{\circ}$ and $0 \%$ $90^{\circ}$ and numerical force-displacement curve of $0^{\circ} / 0^{\circ}$ fin layer orientated panels tested at $6 \mathrm{~m} \mathrm{~s}^{-1}$ using flat striker tip are shown in Fig. 14a. Again, $0^{\circ} / 90^{\circ}$ fin layer orientated panel experiences higher crushing loads than $0^{\circ} / 0^{\circ}$ fin layer orientated panel. The numerical model loads also well approximate the experimental loads in $0^{\circ} / 0^{\circ}$ fin layer orientation, except the loads in the densification region. The pictures of $0^{\circ} / 90^{\circ}$ and $0^{\circ} / 0^{\circ}$ fin layer orientated panels tested with flat striker tip are sequentially shown in Fig. 14b and c. As noted in Fig. 14b and c, the final deformation shapes and displacements of the panels are similar in both orientations. Similar with spherical indenter tip, flat intender tip deforms excessively the face sheets without penetration and induces a higher lateral deformation in $0^{\circ} / 90^{\circ}$ fin layer orientated panels. The experimental back face deflections are $2 \mathrm{~mm}$ for $0^{\circ} / 0^{\circ}$ and $1 \mathrm{~mm}$ for $0^{\circ} / 90^{\circ}$ fin layer orientation. The back face deflections are noted to be smaller than those of the panels tested using spherical striker tip. The numerical model final deformed shape of a $0^{\circ} / 0^{\circ}$ fin layer orientated panel shown in Fig. 14d simulates well the experimental deformed shape.

Typical experimental force-displacement curve of $0^{\circ} / 0^{\circ}$ and $0 \%$ $90^{\circ}$ and numerical force-displacement curve of $0^{\circ} / 0^{\circ}$ fin layer orientated panels tested at $6 \mathrm{~m} \mathrm{~s}^{-1}$ using conical striker tip are shown in Fig. 15a.The corresponding pictures of the tested $0^{\circ} / 90^{\circ}$ and $0^{\circ}$ $0^{\circ}$ fin layer orientated panels using conical striker tip are sequentially shown in Fig. 15b and c. The conical striker tip partially penetrates through inter layers of $0 \% 0^{\circ}$ fin layer oriented panel (Fig. 15c), while it perforates $0^{\circ} / 90^{\circ}$ fin layer oriented panel (Fig. 15b). No back face deflection is observed in $0^{\circ} / 0^{\circ}$ fin layer ori- ented panel, while the back face deflection of perforated $0^{\circ} / 90^{\circ} \mathrm{pa}-$ nel is $5 \mathrm{~mm}$. The panel force-displacement responses to conical striker tip are also quite different from those to spherical and flat striker tips. The force exerted by the conical tip in both $0^{\circ} / 0^{\circ}$ and $0^{\circ} / 90^{\circ}$ fin layer orientated panels increases linearly until about $40 \mathrm{~mm}$ (Fig. 15a), as the striker tip penetrates the panel. Above $40 \mathrm{~mm}$ displacement, $0^{\circ} / 90^{\circ}$ fin layer orientated panel force level decreases due to the delamination of the panel layers. The numerical force values and final deformed shape (Fig. 15d) show close similarities with experimental force values and deformation shape. While, a departure from experimental force values are seen in the force-displacement curve of the model after $70 \mathrm{~mm}$ displacement (Fig. 15a). This result is likely due to small differences in the tip radius of conical striker between model and experiment.

The energy absorbing capacities of the panels as function of displacement are shown in Fig. 16. The energy absorption of the panels tested using conical striker tip is comparably smaller especially in $0^{\circ} / 90^{\circ}$ fin layer orientation (Fig. 16). The energy absorptions of the panels tested using flat striker tip are further higher than those of the panels tested using spherical striker tip. The panels show higher energy absorption in $0^{\circ} / 90^{\circ}$ fin layer orientation than $0^{\circ} \%$ $0^{\circ}$ fin layer orientation. As stated earlier, $0^{\circ} / 90^{\circ}$ fin layer orientated panels distribute the load laterally more evenly when tested with spherical and flat striker tips. This also proves a higher potentials $0^{\circ} / 90^{\circ}$ fin layer orientation in distributing the incident impact laterally; hence improving energy absorption capacity of the tested panels. This will be addressed in another study.

The impact of sandwich plates was considered in three different stages of deformation; failure of the top face sheet, core and bottom face sheet $[22,23]$. In the present study the top face sheet failure occurs because of the local indentation of the spherical and flat 


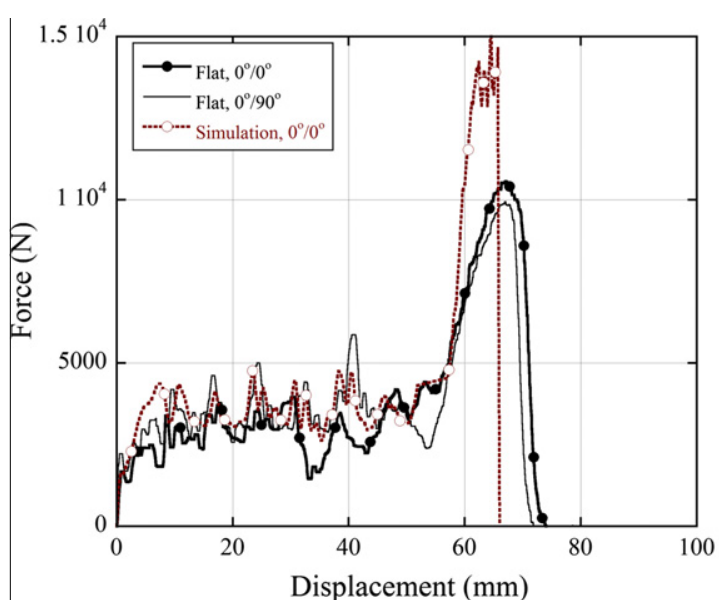

(a)

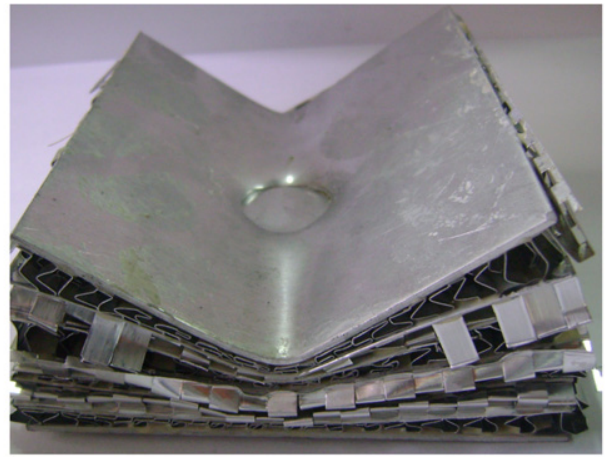

(b)

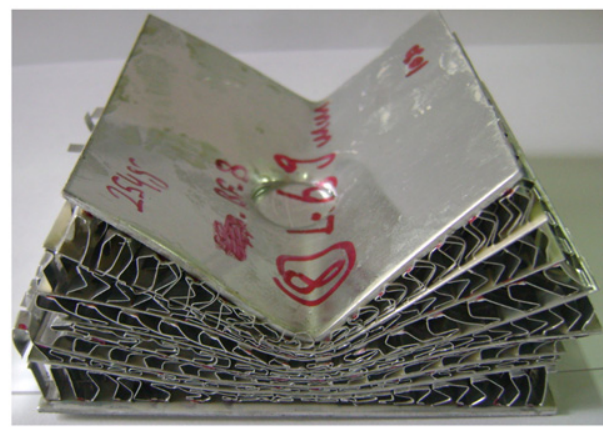

(c)

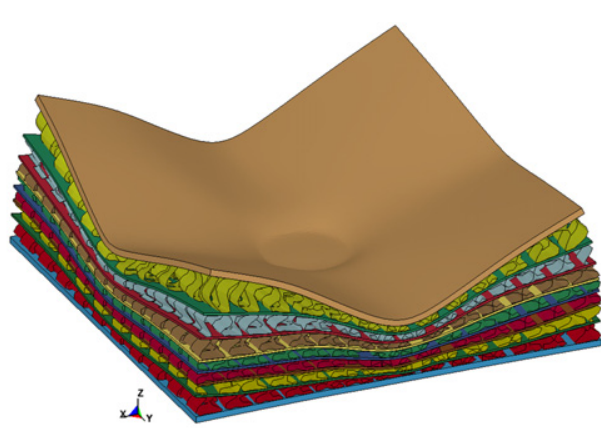

(d)

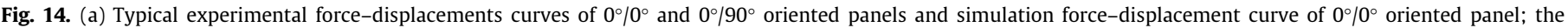
pictures of tested (b) $0^{\circ} / 90^{\circ}$ and (c) $0^{\circ} / 0^{\circ}$ oriented panels and (d) the simulation picture of tested $0^{\circ} / 0^{\circ}$ oriented panel (flat striker tip, the impact velocity is $6 \mathrm{~m} \mathrm{~s}{ }^{-1}$ ).

end strikers. Typical deformation mechanisms include face sheet indentation, core crushing and interlayer sheet bending. As previously reported in a corrugated sandwich plate [10], the debonding between deformed fin and sheet layer sheets is also detected.

The core deformation was shown to be dependent on core density; low density cores deformed by shear and elastic buckling before failure and eventually the core failed by the plastic buckling of the cell walls [24]. These sequences of the deformation also apply to sandwich structure tested in the present study using spherical and flat strikers. It is also noted the low strength brazed fin layers show extensive shearing before fail dominantly by fin wall bending, while the bonded fin layers show more elastic buckling before fail dominantly by fin wall buckling (Figs. 8a and $\mathrm{c}$ and 9a and c). For honeycomb structures to be effective to dissipate the energy of a projectile, the diameter of the projectile should be large as compared with the size of cells [25-27]. For the projectile diameters less than the cell size, the projectile penetrates through the core [22]. When the cell size was large compared to the diameter of the projectile, the sandwich panel with a light weight core showed almost the same resistance to projectile penetration as the face sheet alone [28]. This was due to relatively small contribution of the core deformation during penetration. The penetration of the conical striker to the sandwich panel is therefore due to the relatively small tip radius of the striker compared to the fin width $(5 \mathrm{~mm})$. However, the penetration of a projector can be reduced when the empty places of the core is filled with a relatively rigid material including polymers and ceramics [28].

\subsection{The effect of impact velocity}

Typical force-displacement curves of dynamic $\left(6 \mathrm{~m} \mathrm{~s}^{-1}\right)$ and quasi-static $\left(7 \times 10^{-5} \mathrm{~m} \mathrm{~s}^{-1}\right)$ indentation tests using spherical striker tip and indenter are shown in Fig. 17a. The panel tested dynamically experiences about 1.4 times higher impact loads than quasi-statically tested panel. The effect of drop weight tower impact velocity on the numerical force displacement curve of $0^{\circ} / 0^{\circ}$ fin layer orientated panel is shown in Fig. 17b. As the velocity increases the deformation force values increase; the increase being higher in the region of initial peak load of the curve; although, a rate insensitive material model is used in the simulations.

The deformation rate sensitive crushing loads of cellular materials may result from the strain rate sensitivity of cell wall material, micro-inertial effects, shock wave propagation and compressed air pressure in the cells [29]. As stated earlier, aluminum and its alloys are known to be rate insensitive. The shock wave propagation was shown to have a significant contribution to the strength of the cellular metallic structures over $50 \mathrm{~m} \mathrm{~s}^{-1}$ [30]; therefore, it could not explain the observed deformation rate sensitivity of the tested panels. Micro-inertial effects arise due to lateral inertia, which increases the buckling loads at increasing strain rates [5]. Lateral inertia causes the buckling of a column under impact compression at a delayed time, so that the critical buckling force is higher than the quasi-static one. Calladine and English [5] classified columnar structures in two groups: Type I structures are characterized with a flat-topped quasi-static load deflection curve, showing limited or 


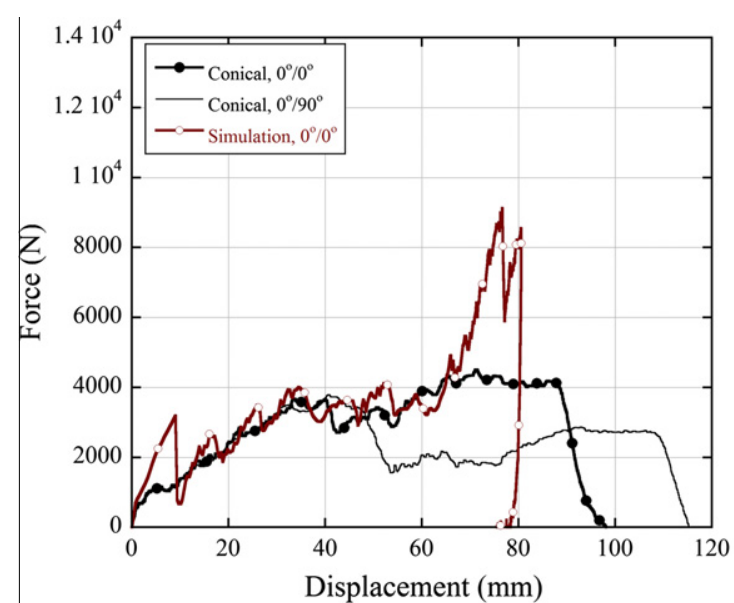

(a)

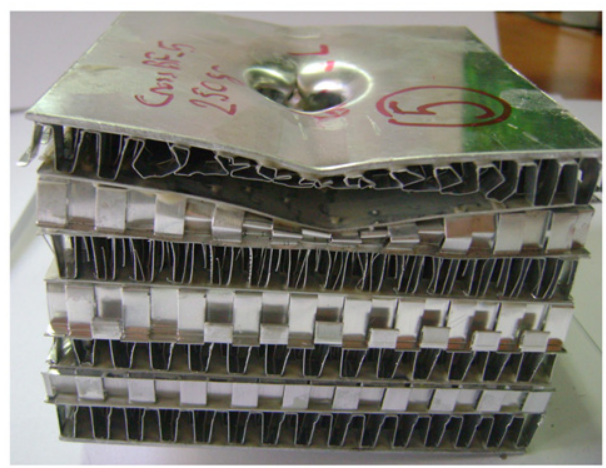

(b)

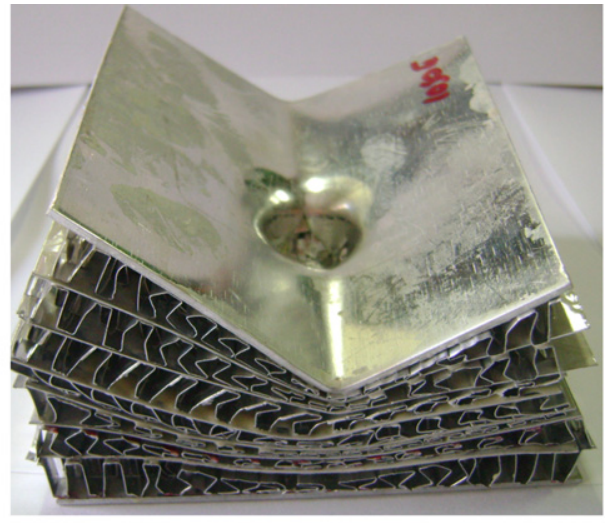

(c)

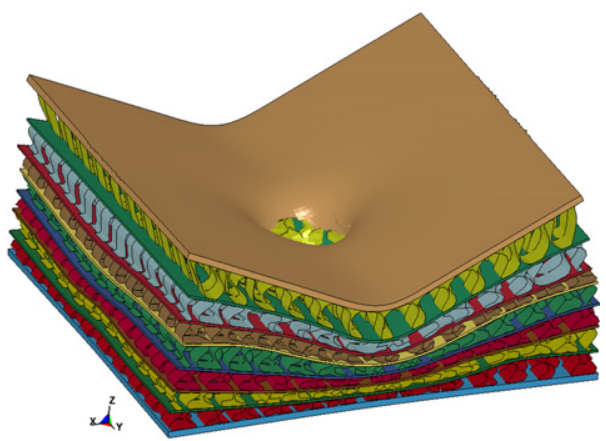

(d)

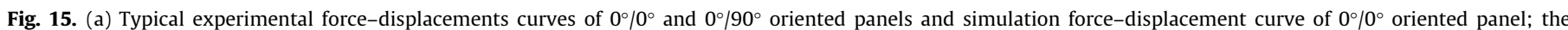
pictures of tested (b) $0^{\circ} / 90^{\circ}$ and (c) $0^{\circ} / 0^{\circ}$ oriented panels and (d) the simulation picture of tested $0^{\circ} / 0^{\circ}$ oriented panel (conical striker tip, the impact velocity is 6 m s ${ }^{-1}$ ).

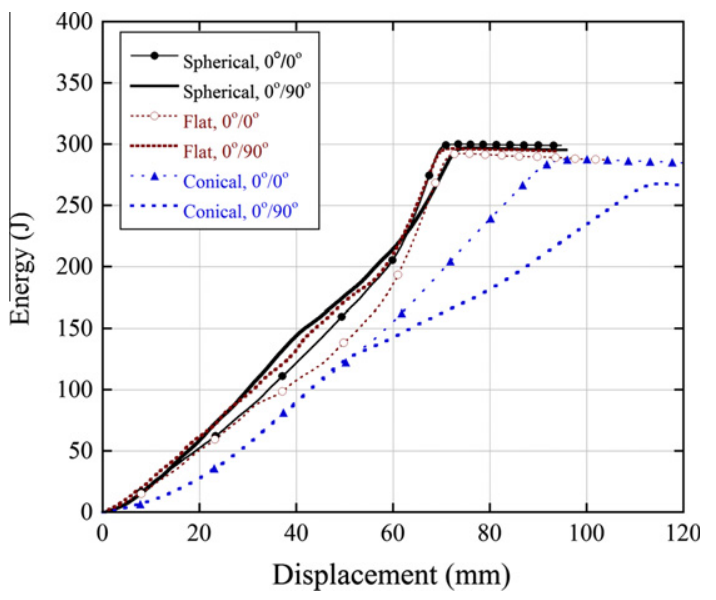

Fig. 16. Energy-displacement history of $0 \% 0^{\circ}$ and $0^{\circ} / 90^{\circ}$ oriented panels tested with spherical, flat and conical striker tips at $6 \mathrm{~m} \mathrm{~s}^{-1}$.

no strength enhancement at increasing deformation velocities and Type II structures are characterized with a strong softening after yielding at quasi-static strain rates and the lateral inertia forces lead to increased bending forces at increasing deformation velocities. The increased deformation forces at increasing strain rates in the compression of aluminum honeycomb structures through out of plane [29], metallic columnar structures [31], aluminum foams [4,29,32], sintered stainless steel hollow spheres [33] and balsa wood in the axial direction $[30,34]$ were reported to result from the micro-inertial effects. The increased peak stresses with increasing impact velocities were also found in periodic cellular metal cores such as Y-frame and corrugated sandwich cores: Y-frame was shown to be less sensitive than corrugated and pyramidal truss cores [8]. The increased initial peak stress of stainless steel pyramidal truss cores [4], textile cellular structures [19] and metallic honeycomb-core sandwich beams [35] at increasing strain rates was reported to be contributed by the inertial effects. In order to differentiate the strain rate hardening and inertial effects, the strain rate parameter of Eq. (1) is taken as zero [4,33]. However, the simulations were executed in the present study by omitting the strain rate hardening. Based on above, it is concluded that micro inertia effect plays a role on the increased force values of the tested panels at increasing velocities.

Lastly, the tests in the present study are apparently prone to specimen size end effects; therefore, cannot show the impact behavior of the panels realistically. However, the full geometrical modeling of the panels with larger sizes leads to extremely increased computational times. On the other side, the agreements between simulation and experimental force values and deformation shapes of relatively small size test panels validate the fidelity of the developed material and full geometrical test model. To model larger sizes of the panels, further investigations should therefore focus on the homogenization methods of layered sandwich structure. 


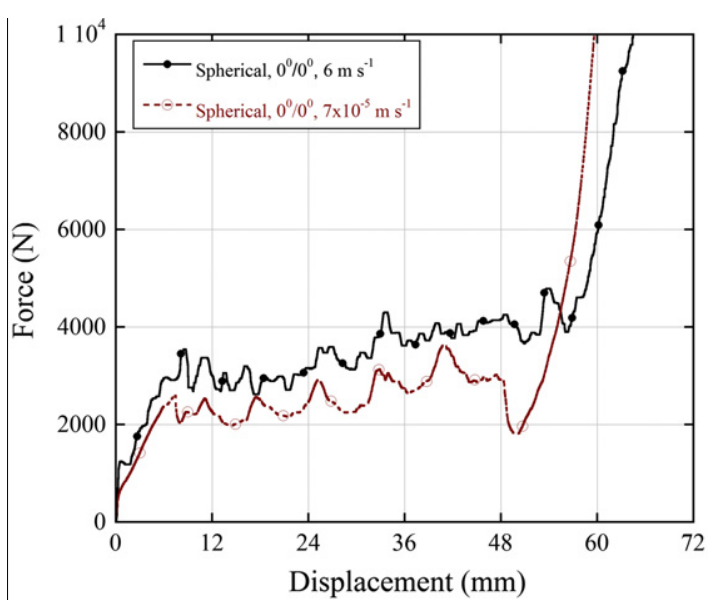

(a)

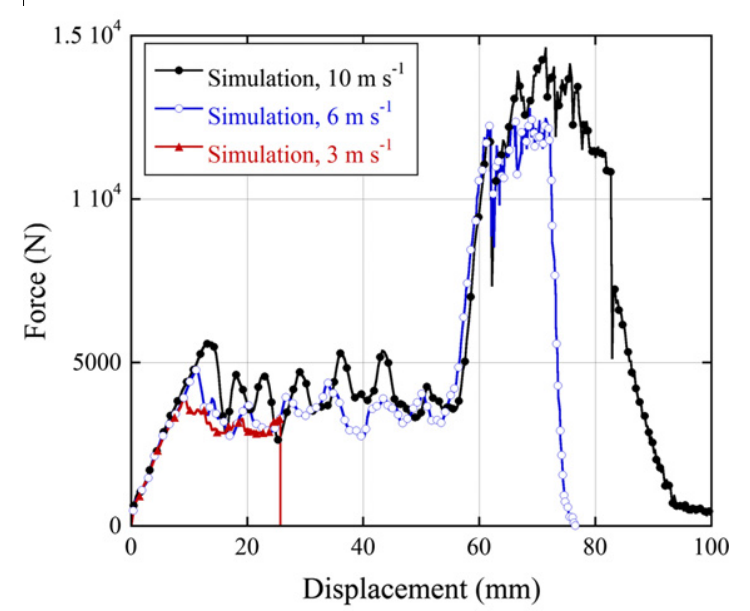

(b)

Fig. 17. (a) Quasi-static and dynamic force-displacement curves of $0^{\circ} / 0^{\circ}$ oriented bonded panels and (b) simulation force displacement curves of $0^{\circ} / 0^{\circ}$ oriented bonded panels tested at 3,6 and $10 \mathrm{~m} \mathrm{~s}^{-1}$.

\section{Conclusions}

The impact responses of layered brazed and adhesively bonded 1050 H14 corrugated aluminum core and aluminum sheet interlayer sandwich panels with 3003 and 1050 H14 aluminum face sheets were investigated in a drop weight tower using spherical, flat and conical end striker tips. The full geometrical models of the tests were implemented using the LS-DYNA. The applied brazing process reduced the crushing loads of the corrugated structures due to the reduced yield stresses of the layers. The adhesively bonded panels tested using spherical and flat striker tips were not penetrated and experienced higher deformation forces and energy absorptions in $0^{\circ} / 90^{\circ}$ corrugated layer orientation than in $0^{\circ} \%$ $0^{\circ}$ orientation. The panels impacted with a conical striker tip were penetrated/perforated and showed comparably smaller deformation forces and energy absorptions, especially in $0^{\circ} / 90^{\circ}$ layer orientation. The panels with $0^{\circ} / 90^{\circ}$ corrugated layer orientation were shown to have potentials of distributing load laterally more efficiently. The simulation and experimental results were found to reasonably agree with each at the large extent of striker impact and revealed the progressive fin folding of corrugated core layer and bending of interlayer and face sheets as the main deformation mechanisms. The experimentally and numerically determined impact velocity sensitivity of the tested panels was attributed to the micro inertial effects which increased the critical buckling loads of the fin layers at increasing loading rates.

\section{Acknowledgment}

The authors would like to thank Cumhur Akar for providing corrugated aluminum core samples.

\section{References}

[1] Liang C-C, Yang M-F, Wu P-W. Optimum design of metallic corrugated core sandwich panels subjected to blast loads. Ocean Eng 2001;28:825-61.

[2] Wadley HNG. Multifunctional periodic cellular metals. Philos Trans R Soc A Math Phys Eng Sci 2006;364:31-68.

[3] Radford DD, Fleck NA, Deshpande VS. The response of clamped sandwich beams subjected to shock loading. Int J Impact Eng 2006;32:968-87.

[4] Lee S, Barthelat F, Hutchinson JW, Espinosa HD. Dynamic failure of metallic pyramidal truss core materials - experiments and modeling. Int J Plast 2006;22:2118-45

[5] Calladine CR, English RW. Strain-rate and inertia effects in the collapse of two types of energy-absorbing structure. Int J Mech Sci 1984;26:689-701.

[6] Rubino V, Deshpande VS, Fleck NA. The dynamic response of clamped rectangular Y-frame and corrugated core sandwich plates. Eur J Mech A: Solids 2009;28:14-24.

[7] Rubino V, Deshpande V, Fleck N. The dynamic response of end-clamped sandwich beams with a Y-frame or corrugated core. Int J Impact Eng 2008;35:829-44.

[8] Tilbrook MT, Radford DD, Deshpande VS, Fleck NA. Dynamic crushing of sandwich panels with prismatic lattice cores. Int J Solids Struct 2007;44:6101-23.

[9] Rubino V, Deshpande VS, Fleck NA. The three-point bending of Y-frame and corrugated core sandwich beams. Int J Mech Sci 2010;52:485-94.

[10] Seong DY, Jung CG, Yang DY, Moon KJ, Ahn DG. Quasi-isotropic bending responses of metallic sandwich plates with bi-directionally corrugated cores. Mater Des 2010;31:2804-12.

[11] Gumruk R, Karadeniz S. A numerical study of the influence of bump type triggers on the axial crushing of top hat thin-walled sections. Thin-Wall Struct 2008;46:1094-106.

[12] Zarei H, Kröger M. Optimum honeycomb filled crash absorber design. Mater Des 2008;29:193-204.

[13] Lim CT, Shim VPW, Ng YH. Finite-element modeling of the ballistic impact of fabric armor. Int J Impact Eng 2003;28:13-31.

[14] Johnson W, Mamalis AG. A survey of some physical defects arising in metal working processes. In: Proceedings of the 17th international MTDR conference, London, UK; 1977. p. 607-21.

[15] Wadley H, Dharmasena K, Chen Y, Dudt P, Oight D, Charette R, et al Compressive response of multilayered pyramidal lattices during underwater shock loading. Int J Impact Eng 2008;35:1102-14.

[16] McShane GJ, Deshpande VS, Fleck NA. Underwater blast response of freestanding sandwich plates with metallic lattice cores. Int J Impact Eng 2010;37:1138-49.

[17] Cote F, Deshpande V, Fleck N, Evans AG. The compressive and shear responses of corrugated and diamond lattice materials. Int J Solids Struct 2006;43:6220-42

[18] Guden M, Yüksel S. SiC-particulate aluminum composite foams produced from powder compacts: foaming and compression behavior. J Mater Sci 2006;41:4075-84.

[19] Lee S, Barthelat F, Moldovan N, Espinosa HD, Wadley HNG. Deformation rate effects on failure modes of open-cell Al foams and textile cellular materials. Int J Solids Struct 2006;43:53-73.

[20] Dharmasena KP, Wadley HNG, Williams K, Xue Z, Hutchinson JW. Response of metallic pyramidal lattice sandwich panels to high intensity impulsive loading in air. Int J Impact Eng 2011;38:275-89.

[21] McShane GJ, Deshpande V, Fleck N. The underwater blast resistance of metallic sandwich beams with prismatic lattice cores. J Appl Mech 2007;74:352-64.

[22] Fatt MSH, Park KS. Perforation of honeycomb sandwich plates by projectiles. Compos Part A - Appl Sci Manuf 2000;31:889-99.

[23] Lin CF, Fatt MSH. Perforation of sandwich panels with honeycomb cores by hemispherical nose projectiles. J Sandwich Struct Mater 2005;7:133-72.

[24] Petras A, Sutcliffe MPF. Indentation failure analysis of sandwich beams. Compos Struct 2000;50:311-8.

[25] Goldsmith W, Sackman JL. An experimental study of energy absorption in impact on sandwich plates. Int J Impact Eng 1992;12:241-62.

[26] Goldsmith W, Louie DL. Axial perforation of aluminum honeycombs by projectiles. Int J Solids Struct 1995;32:1017-46.

[27] Liaghat GH, Nia AA, Daghyani HR, Sadighi M. Ballistic limit evaluation for impact of cylindrical projectiles on honeycomb panels. Thin-Wall Struct 2010;48:55-61.

[28] Yungwirth CJ, Wadley HNG, O'Connor JH, Zakraysek AJ, Deshpande VS. Impact response of sandwich plates with a pyramidal lattice core. Int J Impact Eng 2008;35:920-36. 
[29] Zhao H, Elnasri I, Abdennadher S. An experimental study on the behaviour under impact loading of metallic cellular materials. Int J Mech Sci 2005; $47: 757-74$.

[30] Reid SR, Peng C. Dynamic uniaxial crushing of wood. Int J Impact Eng 1997:19:531-70.

[31] Langseth M, Hopperstad OS. Static and dynamic axial crushing of square thinwalled aluminium extrusions. Int J Impact Eng 1996;18:949-68.

[32] Paul A, Ramamurty U. Strain rate sensitivity of a closed-cell aluminum foam Mater Sci Eng, A 2000;281:1-7.
[33] Tasdemirci A, Ergönenç C, Güden M. Split hopkinson pressure bar multiple reloading and modeling of a 316L stainless steel metallic hollow sphere structure. Int J Impact Eng 2010;37:250-9.

[34] Tagarielli VL, Deshpande VS, Fleck NA. The high strain rate response of PVC foams and end-grain balsa wood. Compos B Eng 2008;39:83-91.

[35] Rathbun HJ, Radford DD, Xue Z, He MY, Yang J, Deshpande V, et al. Performance of metallic honeycomb-core sandwich beams under shock loading. Int J Solids Struct 2006;43:1746-63. 